\title{
Respetable público lector y/o escritor
}

El Editor, los co-editores y el Comité Académico Editorial le dan la más cordial bienvenida y desde ya le hacen un llamado a que se sirvan para sus publicaciones de "Scientific", una Revista de Investigación Socio Educativa, editada trimestralmente por la Editorial del Instituto Internacional de Investigación y Desarrollo Tecnológico Educativo INDTEC, C.A., publicaciones ubicadas en el Sitio web de difusión: http://www.indtec.com.ve/ y https://issuu.com/indtec, con Depósito Legal: BA2016000002 y Registro de Propiedad Intelectual, código Safe Creative: \#1608062119921 / 1609049096099.

La revista Scientific tiene una amplia misión al comprender una publicación multidisciplinaria arbitrada de carácter trimestral, con posibilidad de ser canjeada con otra revista para artículos novedosos e inéditos, ensayos, revisiones y avances de investigación científica generados a lo interno y lo externo de Instituciones de Educación Superior, de las áreas de Gerencia, Educación, Tecnología y Comunicación, los cuales serán sometidos al arbitraje calificado.

Como otra opción que brinda "Scientific", la última sección de la revista se destina a la publicación de contribuciones y ensayos sobre temas vinculados al área académica o social.

Producto de un minucioso trabajo, se detallan las suficientes y necesarias instrucciones a los autores, para que encuentren las orientaciones precisas en la elaboración de los escritos, donde la esencia humana y profesional que distinguen al colectivo editorial que con toda humildad, se encarga de estimular y ayudar para la perfección de cada obra. 
Las puertas están abiertas y serán muy bienvenidas sus producciones, una vez que el equipo de trabajo está convencido, que la divulgación de la investigación científica mediante artículos, ensayos, revisiones, entre otros recursos, es esencial para hacer evidente la realidad de que lo que no se publica no existe y que esta labor culmina al ser publicada en una revista científica; solo así será conocida por la comunidad académica, científica y su contribución hará parte del conocimiento científico universal.

Gracias por tenernos en cuenta. Siempre a las órdenes.

PhD. Isis Angélica Pernas Álvarez (Universidad de Cuenca, UC, Ecuador) 